\title{
Derecho y cine A propósito del crimen de lesa cinematografía
}

\author{
Benjamín Rivaya* \\ Universidad de Oviedo
}

Recibido: 6 de marzo 2016; aceptado: 15 de marzo 2016

\begin{abstract}
Resumen
En tanto que arte narrativo y centrado la mayoría de las veces en la vida social, el cine no ha podido dejar de lado la temática jurídica. Esto es así porque el Derecho no es más que la propia vida social observada desde cierta perspectiva. Las relaciones entre el Derecho y el cine han sido, por lo tanto, de reciprocidad. El Derecho siempre se ha ocupado del cine, sobre todo desde que se convirtió en una gran industria. A su vez el cine, inevitablemente también, se ha ocupado del Derecho pues resulta casi imposible relatar una historia humana sin que aparezca la referencia a la Ley. Este artículo, continuación de otras obras publicadas por el autor, indaga la cuestión en torno a una pregunta crucial: ¿Existe el cine jurídico?
\end{abstract}

Palabras clave: Cine | Derecho | Género | Ley

Cinema and Law

Abstract

As a narrative art that is focused most of the times on social life, the cinema has not been able to ignore the topic of Law. That is the case because the Law itself is no more than our very own social life viewed from a certain perspective. Therefore, the bonds between Law and cinema have been of reciprocity. The Law has always taken care of the cinema, particularly ever since the latter became a big industry. At the same time, the cinema has inevitably taken care of the Law, given that it is almost impossible to tell a human story without making any reference whatsoever to the legal field. This article, following other works by the author, explores this topic in the light of a key question: Is there such thing as legal cinema?

Keywords: Cinema | Law | Genre | Field of law

Las relaciones entre el Derecho y el cine han sido, desde el nacimiento de este último, de reciprocidad. El Derecho siempre se ha ocupado del cine, sobre todo desde que se convirtió en una gran industria con algún poder de control sobre las masas. A su vez el cine, inevitablemente también, se ha ocupado del Derecho pues resulta casi imposible relatar una historia humana sin que aparezcan los omnipresentes datos jurídicos. Películas de criminales, de policías y ladrones, de juicios, de matrimonios, de herencias, de cárceles... Todas nos hablan del Derecho. Así todo, hasta en películas en las que no cabría esperarlo aparece el Derecho y la reflexión sobre el fenómeno jurídico. Véase el caso de un clásico en principio poco jurídico, Gilda (Charles Vidor, 1946). Tras narrar la turbulenta vida de los protagonistas, cuando ya el policía argentino se enfrenta al galán, Johnny Farell (Glen Ford), y le reprueba su actitud, le espeta: "Tengo la ley de mi parte. Es una sensación muy cómoda; le aconsejo que la pruebe alguna vez". El Derecho, parecía que ausente hasta aquí (o casi, pues en el trasfondo de la trama se encontraba un asunto de delincuencia económica a gran escala), se cuela en la historia de sopetón y constituye la moraleja: el amor redime, una vida tranquila y feliz es posible, pero únicamente en el marco de la ley y el orden. Mas ahora no importa tanto la estimación que del Derecho ofrece Gilda cuanto la noticia sobre la aparición de la reflexión sobre el Derecho en el discurso cinematográfico. ${ }^{1}$

\section{El derecho y los géneros cinematográficos. ¿Existe el cine jurídico?}

En tanto que arte narrativo y centrado la mayoría de las veces en la vida social, el cine -ya se dijo- no ha podido dejar de lado la temática jurídica, sencillamente porque el Derecho no es más que la propia vida social observada desde cierta perspectiva.

Esto ha sido así desde el comienzo de la historia del cine, por cierto. Quiero decir que el cine mudo tam-

*rivaya@uniovi.es 
bién ha hablado del fenómeno jurídico. Aunque no usara de la palabra hablada, también aquel cine primero presentaba al espectador el mundo jurídico. Basten dos ejemplos para probar la presencia de la temática jurídica en el cine mudo: por una parte el de una película, Intolerance (David WarkGriffith, 1916), compuesta de cuatro mediometrajes de temáticas intensamente jurídicas; por otra el de Charlot, el casi siempre mudo personaje cinematográfico que, en películas como The Kid (1920), City Lights (1930) oModern Times (1935), en las que adopta una interesante perspectiva frente al Derecho.

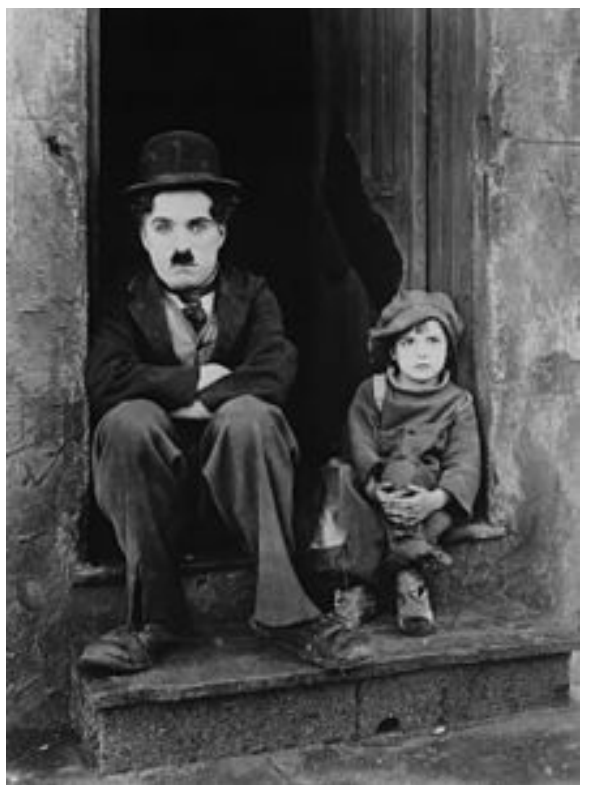

$\mathrm{Si}$ el primer gran criterio distingue entre el cine mudo y el sonoro, también hay que tener en cuenta el de la dramatización de los actores. De nuevo hay que afirmar lo mismo, que tanto el cine documental como el de ficción han tratado asuntos jurídicos. Se podría hablar, por tanto, del documental jurídico, y baste con la referencia a Bowling for Columbine (Michael Moore, 2002), ganadora de un Óscar, que plantea críticamente el problema de los índices de criminalidad existentes en Estados Unidos.

Abarcando el mudo y el sonoro, el de ficción y el documental, entonces, con el rótulo deDerecho y Cine nos referimos a la presencia del fenómeno jurídico en las narraciones cinematográficas, presencia que sin duda ha sido habitual, tan habitual que no resulte extraño que nos preguntemos por la posible existencia del género del cine jurídico. Porque se habla y escribe del cine negro, del bélico, del musical, del western, del de ciencia ficción, del de terror, del melodrama o del cine X, pero no parece que se reconozca aquel otro hipotético género. Realmente la cuestión de los géneros es en gran medida un asunto convencional y, hoy por hoy, parece que aún no existe una convención que lo haya creado. Desde luego, si se pudiera hablar de un cine jurídico sería en referencia al que se dedica a exponer asuntos jurídicos, asuntos que, si fueran reales, que a veces lo son, se verían afectados por las normas y por el pensamiento jurídico, como se ven afectados en las películas; sería un género temático, por tanto (como el cine político, el cine social, el cine religioso, etc.).Desde luego, el ejemplo obvio del cine jurídico sería el de la película estadounidense que narra el proceso seguido por causa penal, sobre todo por asesinato, en el que la acusación solicita casi siempre la pena de muerte (American Criminal Trial Films). Valga como muestra un clásico: Anatomy of a Murder (Otto Preminger, 1959). En cualquier caso, quede claro desde el principio que el cine jurídico no se identificaría con el cine de juicios, que sólo sería una parte de aquél.

El criterio temático que se ha utilizado para acuñar el rótulo de cine jurídico hace que éste pueda solaparse, y de hecho lo haga, con otros géneros reconocidos, determinados a partir de distintas perspectivas. El caso más evidente de solapamiento sería el de la comedia porque no hay problemas para que una comedia trate de asuntos jurídicos e, incluso, se ría del Derecho. Desde luego, podemos hablar sin ningún esfuerzo de comedias jurídicas, uno de cuyos ejemplos clásicos sería el de Adam's Rib (George Cukor, 1949), pero valdrían también otras de Billy Wilder o algunas de los hermanos Marx o de Woody Allen. Más difícil puede parecer la mixtura del musical jurídico, pero desde luego no es imposible: recuérdese Chicago (Rob Marshall, 2002), película típicamente jurídica y musical a un tiempo. Otro tanto cabría decir de los dibujos animados o, mejor, del cine de animación en general, que no necesariamente tiene por destinatario un público infantil o, aun teniéndolo, puede tratar de temas serios, ¡hasta jurídicos!, como ocurre en Antz (Eric Darnell y Tim Johnson, 1998), fábula de hormigas donde se muestra la dialéctica utopía/antiutopía, dialéctica que también se puede observar en otro género en principio ajeno al mundo jurídico, el de la ciencia ficción. Sin embargo, muchas de estas películas también pueden ofrecer materiales para reflexionar sobre el Derecho: Blade Runner (Ridley Scott, 1982) o The Planet of the Apes en sus distintas versiones (Franklin J. Schaffner, 1968; Tim Burton, 2001), por ejemplo. Y aunque pueda parecer gracioso, hasta el cine de romanos sirve para mostrar en imágenes el funcionamiento de las instituciones jurídicas clásicas. Por apuntar alguna, Spartacus(Stanley Kubrick, 
1960) y Gladiator (Ridley Scott, 2000) podrían ser buenos exponentes de ese tipo de películas.

Ahora bien, si es verdad que hay géneros que pueden utilizar o no el dato jurídico, otorgarle mayor o menos importancia, existen algunos que son jurídicos por principio, que no pueden obviar la referencia al Derecho. Se trata del cine negro, del western y del cine político.

El caso del cine negro es paradigmático pues el Derecho siempre aparece en la narración, al menos si aceptamos que se trata de una clase de películas que se ocupa de asuntos criminales y en la que juegan un papel relevante personajes que actúan fuera de la ley o, al menos, en la frontera que separa lo permitido y lo prohibido. Por un lado, gansters, atracadores, chicas de vida fácil, policías corruptos y funcionarios aprovechados que ven las normas jurídicas como obstáculos a sortear; por otro, policías honrados y jueces más o menos razonables, pero también criminales buenos al lado de ciudadanos normales que sufren tanto la ley del hampa como la del Estado. En el cine negro, la línea que separa el bien del mal no la marca la ley. Además, en muchas ocasiones se refleja el problema de una política legislativa errada que prohíbe el consumo de bebidas alcohólicas o el juego con apuestas, y que consigue efectos no sólo indeseados sino indeseables. Valgan como ejemplos Scarface. Shame of a Nation (Howard Hawks, 1932), Fury (Fritz Lang, 1936),High Sierra (Raoul Wash, 1941), Knock on Any Door (Nicholas Ray, 1948) o The Asfalt Jungle (John Huston, 1950).

Como el cine negro, con el que pueden encontrase similitudes, también el western plantea problemas jurídicos fundamentales. De hecho las películas de vaqueros suelen mostrar situaciones anómicas, cuando no existe ley o, en todo caso, no hay quien la imponga. Es curioso que la ausencia de ley, o la ley del más fuerte, se llame la ley del Oeste, y que precisamente las instituciones más típicas del western sean la justicia privada, el tomarse la justicia por su mano, y el linchamiento, la ley de Lynch. Baste con fijarse en dos clásicos para observar distintas génesis y legitimaciones del orden jurídico. En The Man Who Shot Liberty Valance (John Ford, 1962), por más que la violencia juegue un papel en el nacimiento del orden jurídico, es el lockeano pacto de todo un pueblo el que lo fundamenta. En cambio, en The Life and Times of Judge Roy Bean (John Huston, 1972) el Derecho aparece como el resultado de la fuerza descarnada, sin que encuentre en ningún título más noble su justificación. Además, el western incluye las películas de indios y vaqueros, que valen para observar otras relaciones entre el Derecho y el cine, cuando éste se dedicó a legitimar lo que no pocos consideran un genocidio.

Otro género o quasigénero que inevitablemente se halla en contacto con el que llamamos jurídico es el cine político, sencillamente porque el Derecho es un fenómeno político, aunque esta dimensión fundamental suele ocultarse tras el tecnicismo legalista propio de la Jurisprudencia. Para corroborar las relaciones entre el cine político y el jurídico baste con citar The Bird of a $\mathrm{Na}$ tion (D. W. Griffith, 1915), All the King's Men (Robert Rossen, 1949) o, con casi el mismo título, All the President's Men (Alan J. Pakula, 1976).

Pero como ya se ha apuntado, aún no está admitido, y tal vez nunca lo esté, el género del cine jurídico. De lo que no cabe duda, sin embargo, es de la multiplicidad de los argumentos jurídicos en el cine, argumentos que podemos agrupar atendiendo, entre otros criterios, a la habitual clasificación de los sectores del Derecho.

\section{Los argumentos jurídicos en el cine}

Para empezar, véase el caso del Derecho procesal, porque el argumento cinematográfico típicamente jurídico es el juicio, probablemente por la fuerza dramática que tiene la vista, donde intervienen todas las partes afectadas, se tratan cuestiones vitales, acuciantes, y necesariamente hay que tomar una decisión de gran importancia que, hasta que llega, mantiene el suspense de la trama. Repárese por otra parte en el peso del cine norteamericano en la industria cinematográfica, así como en la importancia del proceso en el Derecho anglosajón. No extraña que tantas películas de juicios sean made in USA, ni que sea habitual que en Estados Unidos se hable del género de las películas de juicios. Baste con dos ejemplos. Por una parte, 12 Angry Men (Sydney Lumet, 1957), película excepcional (a mi juicio, el mejor documento fílmico para introducir el estudio del Derecho) en la que el jurado es el protagonista colectivo y en la que se manifiesta como en ninguna otra la dificultad del juicio. Once de los doce miembros del jurado coinciden en apreciar la culpabilidad del acusado; un caso claro, parece. Sólo el que queda problematiza la causa. El ambiente se va caldeando: se aportan argumentos y contra-argumentos, en el debate, y gracias a él, aparecen datos ocultos para todos o casi todos, hay enfados y risas, hay quien quiere marchar y quien recuerda el deber de quedarse, hay explicaciones y justificaciones, y del diálogo, forzado a veces, poco a poco, va surgiendo una decisión razonable. 


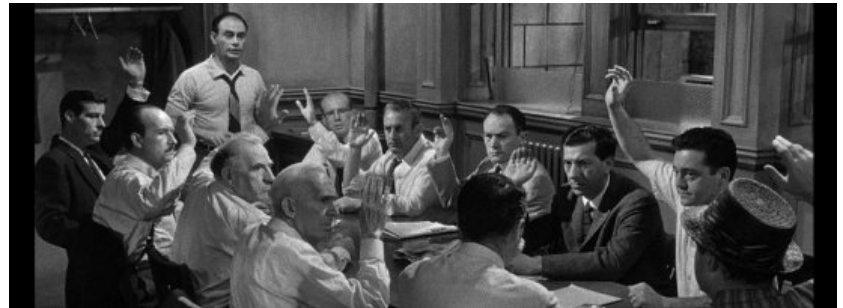

Por otra parte, la ya referida Anatomy of a Murder (Otto Preminger, 1959), otra de las mejores películas de juicios de la historia, y que incluye hasta guiños al pensamiento jurídico: se cita al juez Holmes y se hace referencia al realismo jurídico más extremo, a la jurisprudencia gastronómica. Además, en Anatomía, al igual que en 12 hombres, se observa el carácter dialéctico, argumentativo, del juicio, así como la dificultad de llegar a una decisión correcta de entre las varias posibles.

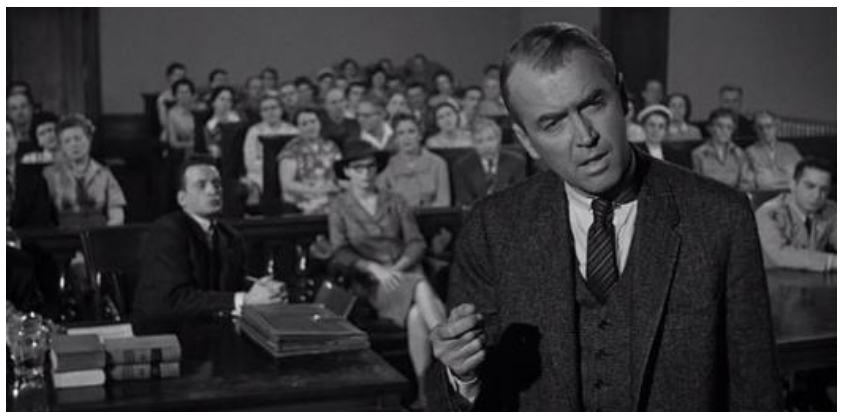

Pero ya quedó visto que el juicio, la vista, no agota la temática jurídica cinematográfica. En la mayoría de los filmes recién citados como ejemplo de películas procesales, de lo que se trata es de asesinatos, crímenes especialmente repugnantes $\mathrm{y}$, a la vez y por eso mismo, fundamentales tópicos cinematográficos. Interesa, por supuesto, cómo se aplican las normas, pero no puede olvidarse que de lo que se trata es de normas penales que castigan el grave delito de dar muerte a una persona. Si el Derecho Procesal es uno de los principales argumentos del cine, el Derecho Penal es el otro, y basta con reenviar a cualquiera de las miles películas de crímenes. Ambos sectores del ordenamiento, el Procesal y el Penal, además, abren la puerta a otros dos argumentos jurídicos típicamente cinematográficos: la cárcel y la pena de muerte, que a veces se agrupan bajo el mismo género penitenciario, pero que permitiría distinguir entre un cine carcelario y otro de la pena de muerte, con muchísimos magníficos ejemplos en ambos casos. Baste con citar dos películas en las que estuvo implicado Tim Robbins y que se tienen, con razón, por paradigmáticas: The Shawshank Redemption (Frank Darabont, 1994) y Dead Man Walking (Tim Robbins, 1995).

Dentro de este largo apartado sobre los argumentos del Derecho en el cine, hay que hacer referencia también al mundo del trabajo, al Derecho Laboral. Recuérdese que una de las primeras cintas que se rodaron en el siglo XIX, en 1895, fue La salida de los obreros de la fábrica Lumière, lo que ya evidenciaba que el mundo del trabajo podía ofrecer argumentos al cine, como todo el siglo XX demostró. Por otra parte, que el trabajo haya sido un argumento cinematográfico no significa que las películas que lo tienen en cuenta sean siempre revolucionarias o militantes, aunque probablemente también sea cierto que el cine laboralista más representativo fue el cine soviético clásico, con películas imprescindibles, caso de Stacka (Sergei M. Eisenstein, 1924) o Mat (Vsievolod Pudovkin, 1926). En los últimos años, probablemente debido a la desaparición del bloque socialista y al imperialismo ideológico liberal, la problemática laboral ha disminuido su presencia en la pantalla, aunque no ha desaparecido. Baste citar a un cineasta comprometido y comercial al mismo tiempo, Ken Loach, que ha rodado obras en las que la circunstancia laboral resulta imprescindible:Riff-Raff (1990) o Raining Stones (1993), por ejemplo, que someten a crítica la política ultraliberal, con sus repercusiones en el mundo del trabajo, de Margaret Tatcher.

Pero además de las ramas jurídicas tradicionales, en el cine también se han reflejado los problemas del Derecho Constitucional y del Derecho Internacional. En cuanto al Derecho Constitucional, tienen especial interés las películas que narran procesos revolucionarios o casos de golpes de Estado.

Recuérdese la magnífica Missing (Costa-Gavras, 1981), que versa sobre el golpe de Estado que Pinochet dirigió en Chile, en 1973, contra el experimento socialista de Salvador Allende.En perspectiva constitucionalista, caben varias lecturas: una avalorativa, y entonces la Constitución chilena, con el golpe, fue derogada y se impuso una nueva; otra crítica, con lo que el régimen constitucional chileno desapareció a cambio de una dictadura militar carente de Constitución (y de escrúpulos): ajena al imperio de la ley, a la separación de poderes y a los derechos fundamentales.

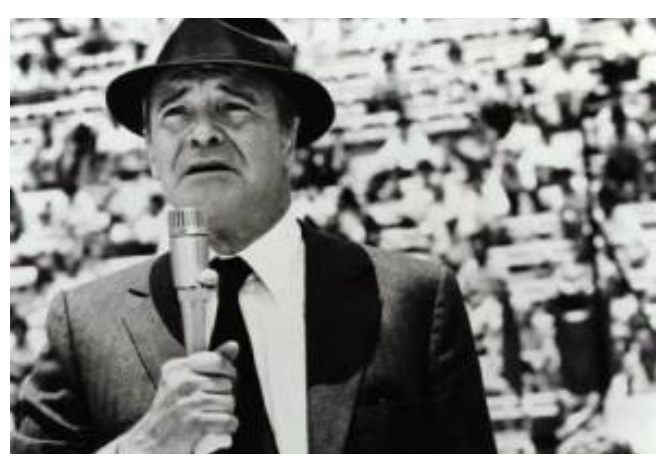


En cuanto al Derecho Internacional, sobre todo han sido las películas de espías y las bélicas, también las que pertenecen al género del cine político, las que más lo han tenido en cuenta, pues no es infrecuente que traten de relaciones internacionales. Como en las que se refieren a los ordenamientos internos, lo que el cine normalmente muestra en éstas es el quebrantamiento de las normas internacionales. Así, la guerra y su justificación, los crímenes de guerra (lo que actualmente lleva a plantear la cuestión de un posible y efectivo Tribunal Penal Internacional) y los derechos humanos, que se pretenden universales, internacionales, son los temas fundamentales de un cine de este tipo. En este ámbito, en el pasado la guerra fría constituyó un filón argumental para el cine que reflejaba la cuestión de las relaciones entre Estados. Aun siendo de 1939, recuérdese la mítica Ninotchka, de Lubitsch.

Ahora bien, de lo dicho hasta aquí parece colegirse que el Derecho que se refleja en las películas es el Derecho Público (el Derecho Penal, el Procesal, el Constitucional, el Penitenciario, el Laboral, que aun si no se tiene por Público presenta rasgos peculiares, etc.), mientras que el Derecho Privado sería el gran ausente del cine. Realmente el Derecho Privado aparece en el cine tanto o más que el Público, aunque llame menos la atención, precisamente por estar implicado en las situaciones más cotidianas de la vida: el matrimonio, la familia, los hijos, la propiedad, la comunidad de vecinos, el seguro, la compra-venta, la herencia... Dentro de este apartado, sin duda ha sido el Derecho de familia el que más argumentos ha proporcionado al cine, con matrimonios felices y matrimonios deshechos, con adulterios, hijos problemáticos, mil asuntos domésticos... Por sólo citar algunos ejemplos, véanse Kramer versus Kramer (Robert Benton, 1979), un melodrama sobre la ruptura matrimonial y el cuidado de los hijos; Green Card (Peter Weir, 1990), el caso de un matrimonio amañado con el que él, francés afincado en Estados Unidos, obtiene permiso de trabajo y ella, joven norteamericana, un apartamento; oIntolerable Cruelty (Joel Coen, 2003), auténtica práctica cinematográfica sobre el régimen económico del matrimonio.

Amén de referencias a sectores concretos del Derecho que ofrecen argumentos cinematográficos, también en el cine podemos encontrar planteadas, o reflejadas al menos, las grandes preguntas de la Filosofía del Derecho. Baste con referirse a Judgment at Nuremberg (Stanley Kramer, 1961), donde se plantea si el Derecho es un producto de la razón o de la voluntad, es decir, la pugna entre el Derecho natural y el positivismo jurídico. Por lo demás, en cuanto a los derechos humanos, son tantos los filmes que tratan de ellos que se podría hablar del género de cine de los derechos humanos, creo yo.

\section{Relación entre las teorías del cine y el derecho}

Pero a los estudios de Derecho y Cine también les han de interesar otras cuestiones, como la de las concepciones del fenómeno fílmico. Creo que se puede afirmar que básicamente existen dos grandes teorías del cine, teorías que reflejan puntos de vista diversos a la hora de observar el fenómeno cinematográfico, por más que quepan posiciones intermedias, mixturas de una y otra. Para la primera, que arranca de la prehistoria del cinematógrafo, una vez que éste pasa a entenderse como algo más que mero divertimento, el cine es el nuevo arte, el séptimo arte, como dijo Riccioto Canudo. Esta visión del cine como arte es propia de muchos cineastas y críticos de cine, y también está vinculada con la concepción del cine como espectáculo.

En cambio, otra doctrina asegura que el cine es sobre todo un fenómeno de propaganda y control social, y es la que se observa en muchas ocasiones entre los científicos sociales, y sobre todo entre los que podemos llamar de izquierdas. La teoría del cine-ideología o del cine-propaganda, que pronto se extendería, tendría muy diversos seguidores pero en su expresión más potente quizás el mayor defensor fue el comunismo, que la popularizó durante décadas. Evidentemente Marx nada había escrito sobre el cinematógrafo, pero los principios teóricos que elaboró podrían ser aplicados para interpretarlo. De hecho Lenin hizo varias referencias al nuevo medio de comunicación de masas, entendiéndolo como un potente instrumento de transmisión de las dos ideologías en confrontación, el capitalismo y el socialismo.

Realmente ambas teorías no son incompatibles; se pueden mantener a un tiempo. Pero si nos quedamos con la primera interpretación del cinematógrafo, entonces carece de importancia para el Derecho; es casi irrelevante. En cambio, si aceptamos la segunda lectura del cine, que lo entiende como un medio de comunicación de masas, se convierte en un instrumento que inevitablemente afecta al Derecho. La traducción iusfilosófica de esta segunda perspectiva reenvía a una clasificación de las películas según que transmitan la idea de que el orden jurídico debe obedecerse o, al contrario, que debe vulnerarse o, por lo menos, someterse a crítica. 


\section{Utilidad de los estudios de derecho y cine}

Así, los estudios de Derecho y Cine pueden reconducirse a la sociología del Derecho. Una sociología del Derecho amplia, que no necesita justificación, ha de ocuparse de los instrumentos utilizados bien para conseguir una obediencia consentida, bien la desobediencia al Derecho. Realmente, el cine y la sociedad mantienen dos tipos de relaciones: aunque de forma más o menos distorsionada, el cine puede reflejar el Derecho y las creencias populares sobre el Derecho, pero también puede participar, y de hecho lo hace, en la conformación de las creencias que tenemos sobre la realidad jurídica. Puede participar en el mantenimiento del estado de cosas (también jurídicas) existente, pero también puede tener un carácter reformista e, incluso, revolucionario. De esta forma aparecería otra rama de la sociología jurídica, la sociología del Derecho en el cine, que habría de integrarse en los estudios más amplios sobre la mentalidad y, en particular, sobre la mentalidad jurídica. En este caso, además, habría que incluir la televisión, pues son la televisión y el cine los más persuasivos medios de control social.

Pero es verdad que las investigaciones que pretenden analizar el tratamiento que el cine otorga al Derecho y, en este sentido, conectan el fenómeno jurídico con el fenómeno cinematográfico, son a todas luces lujosas, es decir, no constituyen una actividad ineludible, no son necesarias; se puede prescindir de ellas. La idea de utilidad entendida como productividad, sin embargo, también es limitada. Nadie actúa solamente con vistas a lograr una productividad material. Quien lo pretende hacer, pronto se verá necesitado de otras prácticas que sólo serán utilitarias en segundo grado y así sucesivamente. Desde luego, la formación de un jurista pudiera quedarse en el aprendizaje de leyes y artículos de códigos, pero pronto se evidenciaría que semejante retención de datos resulta escasa. Ese jurista sería como un historiador que sólo se ocupa de memorizar noticias históricas. Sabemos, sin embargo, que tanto el historiador como el jurista han de ser capaces de conectar unos fenómenos con otros, de tal forma que el objeto de estudio se convierta en legible. Así, conectar dos fenómenos en principio tan ajenos resulta por lo menos una actividad interesante y formativa. El gran sentido de estudios como los de Derecho y Cine consiste en romper con una visión compartimentada de la realidad, que a fuerza de tanta distinción que declara que múltiples facetas de la vida no son interesantes, acaba por convertir en idiota al especialista, que sólo sabe de un sector de la realidad, pero es incapaz de ponerlo en relación con los otros, lo que es tanto como decir que convierte en incomprensible el propio trozo de la totalidad en el que está especializado. Por eso si se quiere una educación jurídica integral, holística, es razonable pedir al estudiante de Derecho que no se ciña sólo a tratados y leyes, y que aprenda hasta del "material no jurídico", también del cine. Así, a nadie ha de extrañar que los recursos audiovisuales se introduzcan en la enseñanza del Derecho, al igual que ya se están usando en otras disciplinas, sin que la novedad haya de entenderse como un atentado contra la tradicional pedagogía jurídica, por otra parte resistente al cambio.

Como las de Literatura y Derecho, las asignaturas de Derecho y Cine tienen un carácter humanístico y merece la pena que sean consideradas en el marco de una formación completa del estudiante de Derecho y de cualquier otra persona interesada simplemente por la realidad social. Desde luego, no soy el único que cree que el cine, bien orientado, tiene mucho que enseñar a los juristas y a quienes se preparan para serlo.

Por obvio, casi no resulta necesario decirlo: una cosa es que el cine y los medios audiovisuales sean interesantes y no se deba prescindir de ellos en la enseñanza, también en la del Derecho, en la que no estaría mal que se incorporaran, y otra que traten de sustituir a la literatura, cosa que no consiguen, aunque eso no quite para que puedan ser un complemento eficaz. La formación jurídica ha de seguir siendo una formación básicamente literaria.

\section{Sobre el crimen de lesa cinematografía y la red iberoamericana de Cine y Derecho}

El lector que amablemente haya llegado hasta aquí se habrá encontrado con una introducción más o menos convincente a los estudios de Derecho y Cine, pero le pueden haber llamado la atención ciertos datos, algunas interpretaciones o aspectos diversos del trabajo. Hay una cuestión que yo mismo he de desvelar, aunque habrá quien ya haya reparado en ella, a quien no se la descubra. Creo que salvo alguna excepción, todo el cine que he citado a lo largo de este trabajo es estadounidense. Como además los experimentos de Derecho y Cine se encuentran muy implantados en Norteamérica, parece que se trata de un todo en uno. Pero no es así. Por más que reconozcamos las virtudes del cine de los Estados Unidos, que muchos filmes de esta nacionalidad son 
auténticas obras de arte y que, por supuesto, también muchas películas norteamericanas son idóneas para los usos de Derecho y Cine (lo que se explicaría bien por su cultura judicial); sin embargo, lo que resulta intolerable es que actúe de pantalla ocultando las demás cinematografías, cuando también estas otras tienen sus virtudes, películas que son obras de arte y productos fílmicos completamente idóneos para Derecho y Cine. En eso consiste el crimen de lesa cinematografía, en la ocultación de una filmografía, que no se conoce y que, incluso, resulta muy difícil sino imposible de encontrar. De esta manera no sólo se pierde un objeto artístico sino un instrumento idóneo para acercarse al estudio de una realidad. Porque la desaparición no sólo perjudica a al cine, ni sólo a Derecho y Cine sino a todos los saberes y el cine: Historia y Cine, Filosofía y Cine, Ética y Cine, Geografía y Cine, Sociología y Cine, Política y Cine, etc.

$\mathrm{Si}$ nos fijamos en las grandes áreas, entre el cine desconocido se encuentra, sobre todo, el africano, pero también el asiático y el latinoamericano. El caso de este último resulta doblemente hiriente porque compartimos una lengua $y$, sin embargo, el cine latinoamericano no llega a España. Desde la perspectiva de Derecho y Cine, se trata de una pérdida lamentable e irreparable que hace que desconozcamos auténticas obras de arte que pueden servir, no por sí solas pero sí con la ayuda de los teóricos correspondientes, para desarrollar el conocimiento.

Entre México y Perú, pero con vocación panamericana, ha nacido la Red Iberoamericana de Cine y Derecho, creada en febrero de 2011, al frente de la cual se hallan José Ramón Narváez y Eddy Chávez, que impulsa los experimentos de Derecho y Cine por toda Latinoamérica; entre ellos también los editoriales, con libros como Cine, ética y argumentación judicial, ${ }^{2}$ coordinado por José Ramón Narvaez; Las elecciones en el cine: un estudio interdisciplinario del séptimo arte y el Derecho electoral, ${ }^{3}$ Los abogados jóvenes y el cine, ${ }^{4} 12$ hombres en pugna. Ni castigo niperdón: el derecho a dudar, ${ }^{5}$ todos ellos coordinados por Eddy Chávez (en el primer caso junto con Michel Samaniego). En breve, probablemente antes de que aparezca este artículo, se publicará Los derechos humanos y el autoritarismo. Una visión desde el cine latinoamericano, coordinado por José Ramón Narváez y Eddy Chávez. ${ }^{6}$

\footnotetext{
1 Para quien quiera ampliar la exposición de este trabajo, le recomiendo Benjamín Rivaya y Pablo de Cima, Derecho y Cine en 100 películas. Una guía básica, Valencia, tirant lo blanch, Valencia, 2004, 502 p.; y Benjamín Rivaya y Luis Zapatero, coords., Los saberes y el cine, Valencia, tirant lo blanch, 2010,670 p., especialmente el capítulo referido a Derecho y Cine.

2 México, Suprema Corte de Justicia de la Na+ción, 2013, 654 p.

3 Lima, Jurado Nacional de Elecciones, 2014, 672 p.

4 Lima, Grijely, 2014, 295 p.

5 Lima, Grijley, 2015, 523 p.

6 Una misión básica de la Red Iberoamericana de Cine y Derecho ha de ser la de reivindicar el cine latinoamericano, visibilizarlo y utilizarlo como fuente de estudio. Por eso, un equipo formado por José Ramón Narváez (México), Mirtha del Río (Cuba), Keymer Ávila (Venezuela), Martín Agudelo Ramírez, César OliverosAya y José Fernando Saldarriaga (Colombia), Eddy Chávez y Alan Felipe Salazar (Perú), Sara Andrade y José Reinaldo Lopes (Brasil), Humberto Mancilla (Bolivia), Daniel Soto Muñoz y Moira Nakousi (Chile), Juan Jorge Michel Fariña e Irene Cambra Badii (Argentina), y Juan Antonio Gómez García y Benjamín Rivaya (España); este amplio equipo ya se encuentra trabajando en este proyecto presente que es Derecho y cine latinoamericano.
} 